\title{
THE IMPORTANCE OF AXIAL TRIRADIUS 'T' IN PREDICTING TREATMENT RESPONSE IN SCHIZOPHRENIA PATIENTS RESISTANT TO CLOZAPINE
}

\author{
Aastha1, Mathangi Santhosh Kumar ${ }^{2}$
}

${ }^{1}$ Associate Professor, Department of Anatomy, CMC and Hospital, Ludhiana, Punjab, India.

${ }^{2}$ Associate Professor, Department of PMR, CMC and Hospital, Ludhiana, Punjab, India.

\begin{abstract}
BACKGROUND
ABSTRACT

Dermatoglyphics is being identified as an important diagnostic aid in a number of diseases having hereditary basis. Genetics play an important role in aetiology of Schizophrenia. A large number of schizophrenia patients are resistant to routine treatment with clonazepam. This resistance has been attributed to a further insult to the nervous system during its development from 'neuroectoderm,' which also gives rise to skin. Hence, any such resistance will be manifested more in the dermatoglyphic prints.
\end{abstract}

\section{MATERIALS AND METHODS}

This is a descriptive study. Study was done on 188 patients of schizophrenia of both sexes (144 treatment responders and 44 treatment non-responders).

\section{RESULTS}

Axial triradius $\mathrm{t}^{\prime}$ was the common position seen in the right hand of the female non-responders. Commonest position was $t$. The $t^{\prime}$ position of the axial triradius is the most common position in both hands of male non-responders.

\section{CONCLUSION}

Amongst all other parameters axial triradius t' stood out as a very important parameter to predict treatment resistance at an early stage. It was found to be significantly important from our study.

\section{KEY WORDS}

Dermatoglyphics, Axial Triradius T, Schizophrenia, Treatment Responders.

HOW TO CITE THIS ARTICLE: Aastha, Kumar MS. The importance of axial triradius 'T' in predicting treatment response in schizophrenia patients resistant to clozapine. J. Evolution Med. Dent. Sci. 2018;7(38):4192-4195, DOI: 10.14260/jemds/2018/937

\section{BACKGROUND}

Skin develops from the germ layer ectoderm and brain develops from the same ectoderm.[1] Finger and palm prints develop on the skin of the hands at 11 to 24 weeks of foetal development. [2],[3] These prints are permanent and they never change during the lifetime of an individual. So it is expected that any insult during the development of brain will result in abnormal development of skin and hand patterns, because the origin of both skin and brain is the same. Now on dermatoglyphic profiles of the hands in schizophrenics, there is evidence.[1],[2],[3] The abnormalities include enlargement of the ventricles and decreased size or function of certain brain regions in people with schizophrenia, which are found in many studies.[2],[4] Schizophrenia may result when neurons form inappropriate and faulty connections during foetal development as found by developmental neurobiologists. The fact that both skin and prints found on it in the hand region and brain are ectodermal derivatives is the basis for studying dermatoglyphic features.

'Financial or Other Competing Interest': None.

Submission 18-07-2018, Peer Review 31-08-2018,

Acceptance 06-09-2018, Published 17-09-2018.

Corresponding Author:

Dr. Mathangi Santhosh Kumar

Department of PMR,

CMC and Hospital,

Ludhiana-141008, Punjab, India.

E-mail:msanthosh365@yahoo.com

DOI: $10.14260 /$ jemds $/ 2018 / 937$
Thus, it can be safely said that disrupted early development can be seen as dermatoglyphic alterations in schizophrenia are markers.[2],[5],[6]

Several authors reported variation in frequency percentage of the finger print patterns in order to establish sex-specific and inter-ethnic variations. But predictor -a biometric feature ffrom another \} uses a challenging research topic.[2],[7]

Dermatoglyphics is to prevent by predicting a disease and identify people with the genetic predisposition to develop certain diseases, but not to diagnose.[2],[5],[6]

- To carry out dermatoglyphic analysis, the palm has been divided into several anatomically defined areas. The ridges usually radiate in three different directions from the point of triradius. There are four digital triradii in the distal portion on the palm. Proceeding in radioulnar direction, they are termed as a, b, c and $d$. The axial triradius ' $\mathrm{t}$ ' is found usually near the proximal palmar margin. The term axial triradius is used for triradius close to the palmar axis. It is found normally near the proximal margin of palm and separates the thenar and hypothenar eminences.

- An axial triradius $(\mathrm{t})$ is usually located near the point where the palm is connected to the wrist.

- $2 \%$ of normal individuals have this triradius positioned near the centre of the palm $(\mathrm{t})$.

- A triradius found halfway in between these two positions $(\mathrm{t}$ ) is found in $21 \%$ of the normal population. 


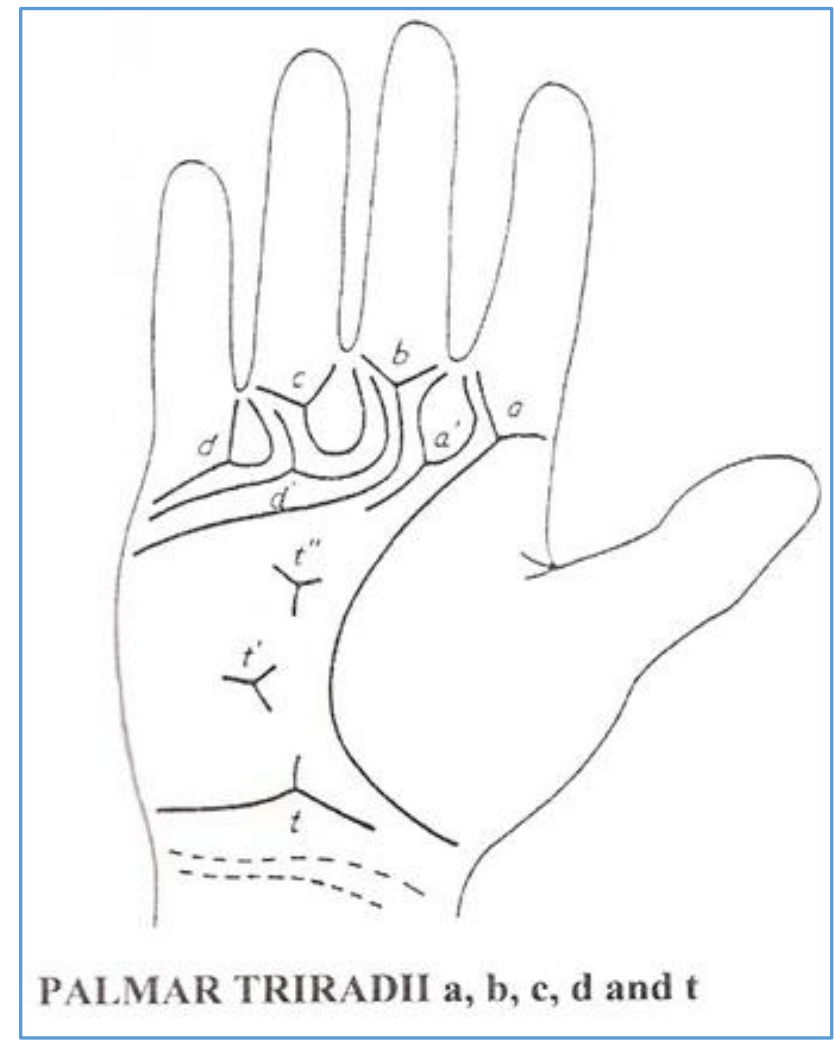

Figure 1. Showing Palmar Triradii

In number of conditions such as Schizophrenia, Turner's syndrome and Congenital heart defect, Mongolism, Down's syndrome, Broad thumb syndrome, Great toe syndrome this triradial point gets displaced. Very less is known as far as axial triradii $\mathrm{t}$ in 'Schizophrenia' is concerned. Dermatoglyphics as a genetic marker is attracting attention of many workers nowadays.

\section{Aims}

1. To determine whether the position of axial triradius $t$, an abnormal neurodevelopmental marker, in schizophrenics non-responsive to treatment was different than those responsive to treatment.

2. Whether treatment resistance can be predicted by studying the axial triradius $t$ and hence the ATD angle of an individual.

\section{MATERIALS AND METHODS}

This is a descriptive study. The study sample consisted mainly of outpatients and some inpatients between 18 and 60 years of age suffering from schizophrenia. 144 of them (86 males and 58 females) were schizophrenics responding to treatment and 44 (35 males and 9 females) were schizophrenics not responding to routine treatment. ${ }^{[2]}$ sample size is taken as per convenience. The patients not responding to treatment were determined by the fact that they were put on clozapine due to drug resistance or other indications like tardive dyskinesia. The patients belonged to the F20 category in ICD-10 classification. Patients were considered treatment resistant using the modified Kane's criteria. The socio-demographic and clinical data and details of psychiatric history were obtained from the patient or from their medical records. All subjects gave informed consent. Finger and palm prints were obtained by the ink and pad method[8] and the analysis of qualitative and quantitative dermatoglyphic features was undertaken with the aid of a magnifying glass. ${ }^{[8],[9]}$

\section{Inclusion Criteria}

All inpatients and outpatients attending the Psychiatry OPD were diagnosed to have schizophrenia (F20-category) by ICD-10 criteria.

\section{Exclusion Criteria}

Patients with following problems were not included in the study-

1. Psychosis untreated.

2. History of obstetrical complications.

3. Patients on other antipsychotics developing tardive dyskinesia.

\section{Materials Used}

1. Paper for taking the prints.

2. Slab.

3. Ink roller.

4. Kores finger print ink.

5. Soap and water for removing the ink from the hands.

After the palm and finger prints were obtained, they were analysed for the position of the axial triradius $t$ and ATD angle.

\section{Statistical Analysis}

Chi-square/ Fisher's exact tests were used for group comparisons.

Independent t-test (for normal data) and Mann-Whitney test (for non-normal data) were performed to compare the mean scores between treatment responders and nonresponders.

Pearson correlation analysis were done to assess the relationship between treatment responders and nonresponders with respect to the ridge counts.

Analysis was carried out using SPSS software vs. 11.0

\section{RESULTS}

\section{T-Axial Triradii Position}

The commonest position in treatment non-responders and responders was the t-position of the axial triradius. The $t^{\prime}$ position of the triradius was seen more in both right and left hands of male non-responders as shown in Table 1. There is significant correlation in the ATD angles in treatment nonresponders and responders (Males and Females).

\section{ATD Angle}

Penrose (1954) observed that the ATD angle is more sensitive to environmental effects. When the ATD angles were compared between treatment responders and nonresponders, statistically significant result was obtained for the left hand as shown in Table 2 and Figure 2. The ATD angles were decreased in treatment non-responders, i.e. around $36.9^{\circ}$ when compared to treatment responders i.e. around $40^{\circ}$. 


\begin{tabular}{|c|c|c|c|c|c|c|c|c|c|c|c|c|}
\hline & \multicolumn{6}{|c|}{ Male } & \multicolumn{6}{|c|}{ Female } \\
\hline & \multicolumn{2}{|c|}{$\begin{array}{c}\text { Treatment } \\
\text { Responders }\end{array}$} & \multicolumn{2}{|c|}{$\begin{array}{c}\text { Treatment } \\
\text { Non-Responders }\end{array}$} & \multicolumn{2}{|c|}{ Total } & \multicolumn{2}{|c|}{$\begin{array}{c}\text { Treatment } \\
\text { Responders }\end{array}$} & \multicolumn{2}{|c|}{$\begin{array}{c}\text { Treatment } \\
\text { Non-Responders }\end{array}$} & \multicolumn{2}{|c|}{ Total } \\
\hline & $\mathbf{N}$ & $\%$ & $\mathbf{N}$ & $\%$ & $\mathbf{N}$ & $\%$ & $\mathbf{N}$ & $\%$ & $\mathbf{N}$ & $\%$ & $\mathbf{N}$ & $\%$ \\
\hline Left & & & & & & & & & & & & \\
\hline $\mathrm{t}$ & 80 & 93.0 & 29 & 82.9 & 109 & 90.1 & 49 & 84.5 & 8 & 88.9 & 57 & 85.1 \\
\hline$t^{\prime}$ & 2 & 2.3 & 5 & 14.3 & 7 & 5.8 & 3 & 5.2 & 1 & 11.1 & 4 & 6.0 \\
\hline$t+t^{\prime}$ & 4 & 4.7 & - & - & 7 & 5.8 & 5 & 8.6 & - & - & 5 & 7.5 \\
\hline $\mathrm{t}+\mathrm{t}^{\prime}+\mathrm{t}^{\prime \prime}$ & - & - & 1 & 2.9 & 1 & 0.8 & 1 & 1.7 & - & - & 1 & 1.5 \\
\hline Right & & & & & & & & & & & & \\
\hline $\mathrm{t}$ & 79 & 91.9 & 30 & 85.7 & 109 & 90.1 & 47 & 81.0 & 9 & 100.0 & 56 & 83.6 \\
\hline$t^{\prime}$ & 2 & 2.3 & 5 & 14.3 & 7 & 5.8 & 2 & 3.4 & - & - & 2 & 3.0 \\
\hline$t+t^{\prime}$ & 4 & 4.7 & - & - & 4 & 3.3 & 8 & 13.8 & - & - & 8 & 11.9 \\
\hline $\mathrm{t}+\mathrm{t}^{\prime}+\mathrm{t}^{\prime \prime}$ & 1 & 1.2 & - & - & 1 & 0.8 & 1 & 1.7 & - & - & 1 & 1.5 \\
\hline
\end{tabular}

\begin{tabular}{|c|c|c|}
\hline & $\begin{array}{c}\text { Treatment } \\
\text { Responders } \\
(\mathbf{N = 1 4 4 )}\end{array}$ & $\begin{array}{c}\text { Treatment } \\
\text { Non-Responders } \\
(\mathbf{N}=44)\end{array}$ \\
\hline $\begin{array}{c}\text { Right Hand } \\
\text { Mean }\end{array}$ & 38.96 & 38.56 \\
SD & 5.07 & 5.56 \\
P value & \multicolumn{2}{|c|}{0.645} \\
\hline Left Hand & 40.00 & 36.91 \\
Mean & 6.79 & 3.83 \\
SD & \multicolumn{2}{|c|}{$0.004^{*}$} \\
P value & Rable 2. ATD Angles in Treatment Non-Responders an \\
\multicolumn{2}{|c}{ Responders } \\
\hline
\end{tabular}

$*$ P value $<0.05$

The mean ATD angle in the right hand of the responders was nearly the same as that of the right hand of the nonresponders and it was not statistically significant.

The mean ATD angle in the left hand of the responders was higher than that of the non-responders and it was statistically significant.

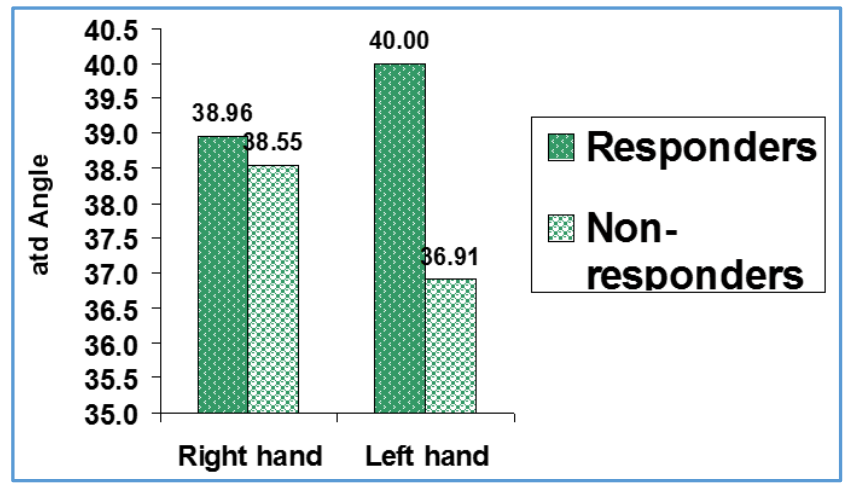

Figure 2. Mean of ATD Angle

\section{DISCUSSION}

A lot of work is done in finding an association of genetic and morphological characters with a number of diseases through certain investigations. Dermatoglyphics is one of such tools frequently used in scientific studies, which are determined by polygenic inheritance.[8] Dermatoglyphic is an important aid in the diagnosing and understanding the genetics of many diseases.

Study on dermatoglyphics in 'mental retardation' by $\mathrm{M}$ Vashisht et al showed 'ATD' angle $>65^{\circ}$ in right and left hands of the cases as compared to controls. In this study many dermatoglyphic parameters were studied and were significant statistically. $\mathrm{T}$ position was seen in $47.4 \%, \mathrm{t} /$ in $24.8 \%, \mathrm{t} / /$ in $27.8 \%$ in mentally retarded and $\mathrm{t}-74.8 \%, \mathrm{t} /$ in $21 \%, \mathrm{t} / /$ in $4.2 \%$ as normal.

In our study, $93 \%$ of males in treatment responder category had position $t$ in their left hand. $2.3 \%$ of males in treatment responder category had position $t^{\prime}$ in their left hand. $\mathrm{t}^{\prime \prime}$ position was not seen in this category. And $91.9 \%$ males had position $t, 6.7 \%$ had $t ', 1.2 \%$ had position $t^{\prime \prime}$ in their right hand. Amongst females in treatment responder category $84.5 \%$ had position $t, 5.2 \%$ position $t^{\prime}, 8.6 \%$ position $t^{\prime \prime}$ in their left hand. And $81 \%$ had position $t, 16.8 \%$ had position $t^{\prime}$ and $1.7 \%$ had $t^{\prime \prime}$ in their right hand.

Males in treatment non-responder category had position $\mathrm{t}$ in $82.9 \%$ and position $t^{\prime}$ in $14.3 \%$ in their left hand. Position $t^{\prime \prime}$ was not seen in the left hand here. And $85.7 \%$ had position $t$ and $14.3 \%$ had position $t^{\prime}$ in their right hand. Position $t^{\prime \prime}$ was not seen in the right hand of the males of treatment nonresponder category. Females in treatment non-responder category had $88.9 \%$ position $\mathrm{t}, 11.1 \%$ position $\mathrm{t}^{\prime}$ in left hand. Again, position t" was not seen in their left hand. And 100\% females in treatment non-responder category had position $t$ in their right hand. Position $t^{\prime}$ and $t^{\prime \prime}$ were not seen here.

The study of abnormalities in dermatoglyphics has been used in various of chromosomal disorders, neurological, neuropsychiatric conditions and congenital malformations in order to gain insight into the complex interaction of developmental, environmental and genetic factors leading to the disease.[9],[10] Schizophrenia, diabetes mellitus, congenital heart disease, Down's syndrome,[11],[12] fragile X-syndrome.[13] Brachmann-de Lange syndrome, bipolar disorder,[14] leukaemia and thalassemia are a few conditions associated with dermatoglyphic abnormalities.

Dermatoglyphics are formed in the embryonic phase. Generally, dermatoglyphics remain unchanged throughout an individual's life.[12]

A number of physiological insults that can occur during foetal development including exposure to environmental toxins, viral infections or genetic mutations which can be seen with malformations of dermatoglyphic characteristics. In early foetal development differentiation of epidermal ridges takes place. The ridge pattern is affected by environmental factors and can also be genetically determined.[15] Schizophrenia is a chronic recurring illness, which is prominently characterised by reality distortions 
(Hallucinations and Delusions), thought disorder, cognitive dysfunction and negative symptoms. From ectoderm brain and skin development ${ }^{[1]}$ and cells migrate to the cortex at this time. An insult causing damage to one of these systems might damage the other probably. In the hands to schizophrenia, there is now evidence relating aspects of the dermatoglyphics profiles.[1],[3] While there is compelling evidence of a genetic component[16] in the development of schizophrenia, the precise nature of this is yet to be fully elucidated. There is a lot of evidence available that environmental factors acting during the prenatal and perinatal periods exert an effect that leads to the subsequent development of schizophrenia.[17] The second trimester is a period of potential vulnerability of foetal development.[18] For both foetal brain and epidermal ridge development, this trimester is the critical period. The more severe the genetic insult to the developing brain, the more disrupted will dermatoglyphic pattern be.

So in our study, the commonest position in treatment responders and non-responders was the $t$ position of the axial triradius. The $t^{\prime}$ position of the triradius was seen more in both hands of male non-responders. Most striking observation is seen in the right hands of the females in the non-responder group, where none of them show presence of either $\mathrm{t}^{\prime}$ or $\mathrm{t}^{\prime \prime}$ position.

But some other authors like Sarthak Sengupta et al found the percentage frequencies of axial triradii ' $t$ ' dominant among control males, ' $t$ ' highest among Schizophrenic males and ' $t / /$ ' higher among Schizophrenic females.

\section{CONCLUSION}

'Schizophrenia' is genetically transmitted, so are dermatoglyphic patterns. There was statistical significance in comparison with controls, as many dermatoglyphic patterns are seen in 'Schizophrenia' patients. Axial triradius t' was more common in right hand of the females in responder group. Axial triradius t' and t" were not seen in the right hands of the female non-responders. Commonest position seen was $t$. The $t^{\prime}$ position of the axial triradius is the most common position in both hands of male non-responders. In both males as compared to females in patients as well as controls, the 'ATD' angle is reduced.

A larger sample with patient's relatives is required to know if dermatoglyphics can be used as a screening or investigative procedure for other brain disorders.

Our research confirms that certain abnormal neurodevelopmental markers were more frequent in schizophrenics non-responding to routine treatment.

On studying the dermatoglyphic profile, a patient likely to develop treatment resistance, can be detected.

\section{REFERENCES}

[1] Van Oel, Baare WF, Pol HHE, et al. Differentiating between low and high susceptibility to schizophrenia in twins: the significance of dermatoglyphic indices in relation to other determinants of brain development. Schizophr Res 2001;52(3):181-93.

[2] Aastha, Isaac B, Mathangi SK. Dermatoglyphic patterns as possible predictors of treatment resistance in schizophrenia. Journal of the Anatomical Society of India 2014;63(2):110-6.
[3] Fearon P, Lane A, Airie M, et al. Is reduced dermatoglyphic $a-b$ ridge count a reliable marker of developmental impairment in schizophrenia? Schizophr Res 2001;50(3):151-7.

[4] Johnstone EC, Crow TJ, Frith CD, et al. Cerebral vascular size and cognitive impairment in chronic schizophrenia. Lancet 1976;308(7992):924-6.

[5] Murray RM, Lewis SW. Is schizophrenia a neurodevelopmental disorder? British Medical Journal (Clinical Research Ed) 1987;295(6600):681-2.

[6] Bramon E, Murray RM. A plausible model of schizophrenia must incorporate psychological and social, as well as neuro developmental risk factors. Dialogues in Clinical Neuroscience 2001;3(4):243-56.

[7] Golembo-Smith S, Walder DJ, Daly MP, et al. The presentation of dermatoglyphic abnormalities in schizophrenia: a meta-analytic review. Schizophrenia Research 2012;142(1-3):1-11.

[8] Mellor CS. Dermatoglyphics in schizophrenia. Part 1. Qualitative aspects. British Journal of Psychiatry 1968;114(516):1387-97.

[9] Chakraborty R. The role of heredity and environment on dermatoglyphic traits. Birth Defects Original Article Series 1991;27(2):151-91.

[10] Schaumann BA, Opitz JM. Clinical aspects of dermatoglyphics. Birth Defects Original Article Series 1991;27(2):193-228.

[11] Rajangam S, Janakiram S, Thomas IM. Dermatoglyphics in Down's syndrome. Journal of the Indian Medical Association 1995;93(1):10-3.

[12] Sun L, Castellanos N, Grutzner C, et al. Evidence for dysregulated high-frequency oscillations during sensory processing in medication-naive, first episode schizophrenia. Schizophrenia Research 2013;150(23):519-25.

[13] Loesch DZ, Huggins RM, Taylor AK. Application of robust pedigree analysis in studies of complex genotype-phenotype relationships in fragile $\mathrm{X}$ syndrome. American Journal of Medical Genetics 2002;107(2):136-42.

[14] Torrey EF. Epidemiological comparison of schizophrenia and bipolar disorder. Schizophrenia Research 1999;39(2):101-6.

[15] Bhat GM, Mukhdoomi MA, Shah BA, et al. Dermatoglyphics: in health and disease - a review. Int J Res Med Sci 2014;2(1):31-7.

[16] Gottesman II, Shields J. Schizophrenia in twins: sixteen years consecutive admissions to a psychiatric clinic. Brit J Psychiatric 1966;112(489):809-18.

[17] Murray RM, O'Callaghan E, Castle DJ, et al. A neurodevelopmental approach to the classification of schizophrenia. Schizophr Bull 1992;18(2):319-32.

[18] Mednick SA, Machon RA, Huttunen MO, et al. Adult Schizophrenia following prenatal exposure to an influenza epidemic. Archives of General Psychiatry 1988;45(2):189-92. 